\title{
An unusual case of Sirenomelia Sympus Dipus (Mermaid Syndrome)
}

\author{
Jenny Hoque ${ }^{1}$, Efterpi Tingi ${ }^{2 *}$, Sanjay Sinha ${ }^{3}$ and Vincent Bamigboye ${ }^{3}$ \\ ${ }^{1} \mathrm{GP}$ trainee, Department of Obstetrics and Gynaecology, Furness General Hospital, Barrow-in- Furness, UK \\ ${ }^{2}$ Specialty registrar in Obstetrics and Gynaecology, Department of Obstetrics and Gynaecology, Furness General Hospital, Barrow-in- Furness, UK \\ ${ }^{3}$ Consultant in Obstetrics and Gynaecology, Department of Obstetrics and Gynaecology, Furness General Hospital, Barrow-in- Furness, UK
}

\begin{abstract}
Sirenomelia or mermaid syndrome is a rare and fatal congenital condition, which is not associated with chromosomal anomalies. The fusion of the lower extremities characterizes it to form one single lower limb and its aetiology remains unclear. We report a rare case of 32-year-old woman who had a successful pregnancy following in-vitro-fertilization. A first trimester scan showed decreased liquor volume therefore she was referred to fetal medicine unit for a detailed scan at 22 weeks of gestation which showed bilateral thorax hypoplasia, bilateral renal agenesis and anhydramnios. The baby was delivered with the unexpected sirenomelia congenital anomaly and died four hours after birth.
\end{abstract}

\section{Introduction}

Sirenomelia or mermaid syndrome is a rare and fatal congenital condition, which was first described by Rocheus in 1542 [1]. It affects 1 in 100,000 live births worldwide, with the male to female gender ratio being 3:1 [2]. Its name originates from Greek mythology as Siren [1]. The fusion of the lower extremities characterizes the condition to form one single lower limb [3]. It is described as the most severe form of caudal regression syndrome and is often associated with bilateral renal agenesis and severe pulmonary hypoplasia [4]. Common risk factors include maternal drug abuse, maternal diabetes mellitus and consanguineous marriages with underlying genetic predispositions $[5,6]$. We describe the case of a baby with Sirenomelia: Sympus Dipus born to a Bengali mother following In Vitro Fertilization (IVF) treatment.

\section{Case presentation}

A 32-year-old primigravida woman with no comorbidities, underwent her third cycle of IVF which was successful. Her husband did not have any comorbidities or children from a previous relationship.

A departmental scan in early pregnancy locally showed reduced amniotic fluid volume and the fetal bladder was not seen (Figure 1). She was then subsequently referred to Fetal Medicine Unit (FMU) at 22 weeks of gestation for more detailed scan, which confirmed bilateral thorax hypoplasia, bilateral renal agenesis and anhydramnios. The bladder was not visualized and all the other fetal structures appeared normal.

Following these scans, she was offered termination of pregnancy at 23 weeks and 3 days gestation in view of the poor prognosis, however she decided to continue with the pregnancy. Further opinion was obtained by another FMU in the region and a plan was made not to monitor fetal heart rate intrapartum and to inform the neonatal team after delivery for palliative or terminal care for the newborn baby.

At 39 weeks gestation, external cephalic version was attempted but it was unsuccessful. She presented at 40 weeks gestation, with an episode of vaginal bleeding therefore she underwent elective cesarean section as planned for the transverse lie of the baby. An inverted $\mathrm{T}$ incision was done and the baby was delivered with the unexpected sirenomelia congenital anomaly. The baby weighed $2155 \mathrm{~g}$ and passed away peacefully within four hours of delivery.

On external examination of the baby, one umbilical artery was seen. There were no external genitalia to determine the sex and no anus present. The extremities and both feet were fused with webbing of the toes (Figure 2). The baby had typical Potters sequence facies including a flattened nose, prominent bilateral epicanthal folds, low set ears and a receding chin. Due to religious reasons, the baby did not have any imaging or genetic testing, nor was a post mortem done.

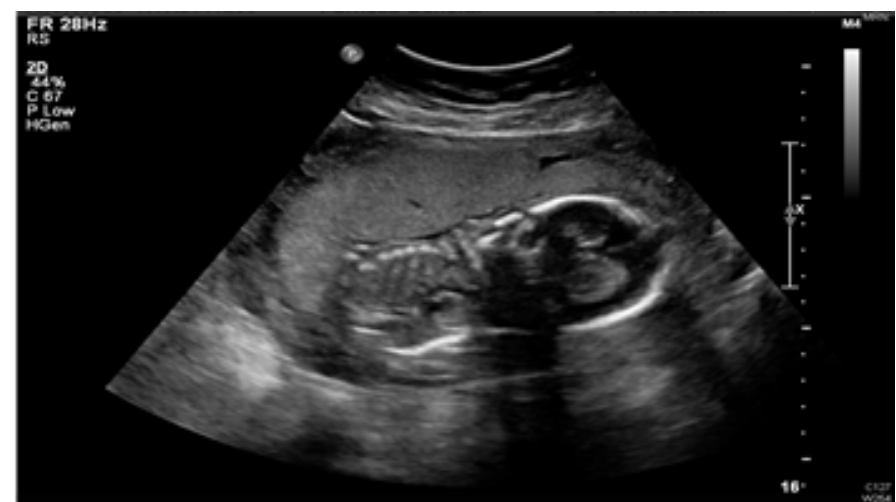

Figure 1. Local Ultrasound scan at 20 weeks and 4 days gestation

Correspondence to: Efterpi Tingi, Department of Obstetrics and Gynaecology, Furness General Hospital, Dalton Lane, L14 4LF, Barrow in Furness, UK, Tel: 0044-7796025836, Fax: 0044-1229 871047, E-mail. efterpi.tingi@doctors.org.uk

Received: August 26, 2017; Accepted: September 22, 2017; Published: September 26, 2017 


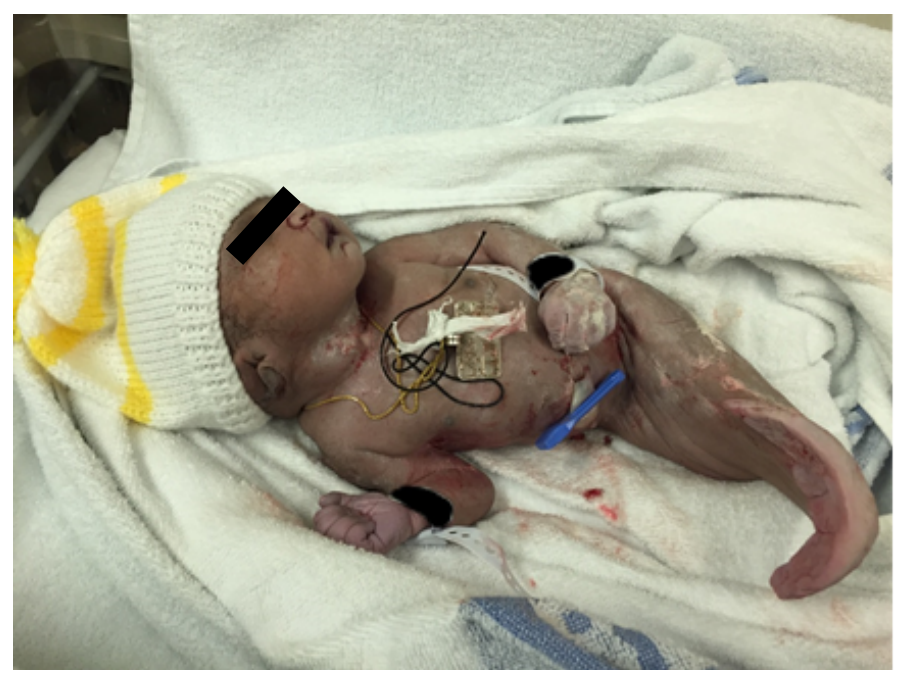

Figure 2. Term baby with sirenomelia sympus Dipus

\section{Discussion}

Sirenomelia sympus dipus is a part of caudal regression syndrome but this has its own pathogenesis and exists as its own entity. Aetiology of sirenomelia remains unclear but it is known to be caused by an embryological injury that occurs between 28 and 32 days of development at the caudal mesoderm [1]. In a study by Stevenson et al. [7]. 11 cases of sirenomelia were examined and showed a pattern of vascular abnormalities. The common feature demonstrated was a single large abdominal artery which functions the umbilical arteries. The nutrients for this are diverted away from the caudal end of the embryo distal to the level of its origin. An early embryonic vascular network which supplies the yolk sac, has the steal vessel. It is formed from the vitelline artery complex and arteries below this vessel are underdeveloped, therefore any tissues formed from this vessel fail to have the nutrient supply thus leading to malformation of the lower extremities [7].

Another study has proposed the theory that oxidative metabolism from maternal diabetes may play a role as this can cause free oxygen radicals in the developing embryo leading to teratogenicity and mutation [1]. This baby had typical Potters sequence facies caused by pressure in utero due to the oligohydramnios. It is known to commonly affect male babies and is present with bilateral pulmonary hypoplasia and severe oligohydramnios due to bilateral renal agenesis [8].

Currently there is no serum marker for sirenomelia to detect it antenatally. Early scanning is recommended to identify these gross anomalies early in order to provide alternative management to the pregnancy. Ultrasound usually makes prenatal diagnosis mostly during the late second and third trimesters with the confirmation of combination of malformation of the lower limbs and decreased amniotic fluid volume, related to urinary tract agenesis or dysgenesis; these findings become visible after the end of the first trimester [9]. like in our case. There are many cases with severe oligohydramnios reported in the literature, in which sirenomelia was diagnosed only following delivery of the baby [10]. The first trimester prenatal diagnosis of the syndromes is very rare as because of the size of the fetus, which can make it challenging.

Prognosis is very poor with babies being still born or passing away immediately after birth due to agenesis of the kidneys and pulmonary hypoplasia which are incompatible with life after birth [11]. Early diagnosis of sirenomelia, gives the parents the option to safely terminate the pregnancy early, in order to prevent the psychological effects associated with this condition. Patients who are at risk of this fatal condition should be offered early scanning to correctly identify these anomalies to help counselling of the parents and prepare them for the outcome. Finally, this case illustrates the importance of accessing multidisciplinary team when a rare and unusual case presents.

\section{Acknowledgements}

We would like to thank the parents of this baby for allowing us to write about this case, in order for us to learn from this case and further our medical education in this teaching hospital. Informed consent was taken from the parents for the purpose of this publication.

\section{References}

1. Kshirsagar VY, Ahmed M, Colaco SM (2012) Sirenomelia Apus: A Rare Deformity. $J$ Clin Neonatol. 1: 146-148. [Crossref]

2. Samal SK, Rathod S (2015) Sirenomelia: The mermaid syndrome: Report of two cases. J Nat Sci Biol Med 6: 264-266. [Crossref]

3. Gul Z, Jan AZ, Liaqat F, Khan HA (2013) Sirenomelia, the mermaid syndrome. Gomal J Med Sci 11:114-116.

4. Das BB, Rajegowda BK, Bainbridge R, Giampietro PF (2002) Caudal regression syndrome verses sirenomelia: A case report. J Perinatol 22: 168-170.

5. Seidahmed MZ, Abdelbasit OB, Alhussein KA, Miqdad AM, Khalil MI, et al. (2014) Sirenomelia and severe caudal regression syndrome. Saudi Med J 35: S36-S43. [Crossref]

6. Nosrati A, Naghshavar F, Torabizadeh Z, Emadian O (2013) Mermaid syndrome, Sirenomelia: A case report and review of literature. J Pediatr Rev 1: 64-69.

7. Stevenson RE, Jones KL, Phelan MC, Jones MC, Barr M Jr, et al. (1986) Vascular steal: the pathogenetic mechanism producing sirenomelia and associated defects of the viscera and soft tissues. Pediatrics 78: 451-457. [Crossref]

8. Srikanth M. Shastry, Sachin S Panduranga R. Sanagapati (2012) Potter's Sequence. $J$ Clin Neonatol 1: 157-159. [Crossref]

9. Akbayir O, Gungorduk K, Sudolmus S, Gulkilik A, Ark C (2008) First trimester diagnosis of sirenomelia: a case report and review of the literature. Arch Gynecol Obstet 278: 589-592. [Crossref]

10. Carbillon L, Seince N, Largillière C, Bucourt M, Uzan M (2001) First-trimester diagnosis of sirenomelia. Fetal Diagn Ther 16: 284-288.

11. Ramesh KR, Srinivas S, Kumar S, et al. (2012) Sirenomelia: A Rare Presentation. $J$ Neonatal Surg 1: 7. [Crossref]

Copyright: (C2017 Hoque J. This is an open-access article distributed under the terms of the Creative Commons Attribution License, which permits unrestricted use, distribution, and reproduction in any medium, provided the original author and source are credited. 